TREE-RING RESEARCH, Vol. 60(2), 2004, pp. 101-104

\title{
BIBLIOGRAPHIC COMMUNICATION
}

\section{THE BIBLIOGRAPHY OF DENDROCHRONOLOGY AND THE GLOSSARY OF DENDROCHRONOLOGY: TWO NEW ONLINE TOOLS FOR TREE- RING RESEARCH}

\author{
MICHÈLE KAENNEL DOBBERTIN* \\ WSL Swiss Federal Research Institute \\ CH-8903 \\ Birmensdorf, Switzerland \\ and \\ HENRI D. GRISSINO-MAYER \\ Department of Geography \\ University of Tennessee \\ Knoxville, TN 37996, USA
}

\begin{abstract}
Two new online products are available to the international tree-ring community. The Bibliography of Dendrochronology (published online in February 2003) currently has 10,000 references and is the world's largest online bibliography specializing in tree-ring research. In March 2004, the Glossary of Dendrochronology was made available and is a searchable database of 351 terms and definitions in English, German, French, Spanish, Italian and Portuguese. Both databases result from the collaboration of numerous treering scientists worldwide.
\end{abstract}

Keywords: Dendrochronology, online resources, bibliography, multilingual glossary.

\section{INTRODUCTION}

Dendrochronology is a scientific method at the crossroad of many scientific disciplines. It borrows ideas from such areas as wood anatomy, isotope analysis, and chemistry, and serves such disciplines as archaeology, climatology, hydrology and forest ecology. An active international tree-ring community has grown over time operating through the Internet since 1988 when the International Tree-Ring Data Bank (ITRDB) created a discussion forum that thrives today. Networking activities within this community involve, for example, the online International Tree-Ring Data Bank, two

* Corresponding Author: kaennel@wsl.ch journals (Tree-Ring Research and Dendrochronologia), two professional associations (the TreeRing Society and the Association for Tree-Ring Research), the ITRDB Internet Forum, and numerous excellent web sites (Grissino-Mayer 19962004).

Two new online resources further contribute to the dissemination of information and help foster international collaboration within this community. Since February 2003, the Bibliography of Dendrochronology ${ }^{1}$, a wealth of over 10,000 references related to tree-ring analysis, has been available and

\footnotetext{
${ }^{1}$ Bibliography of Dendrochronology: http://www01.wsl.ch/ dendrobiblio, cited 01-Apr-04.
} 


\section{Bibliography of Dendrochronology}

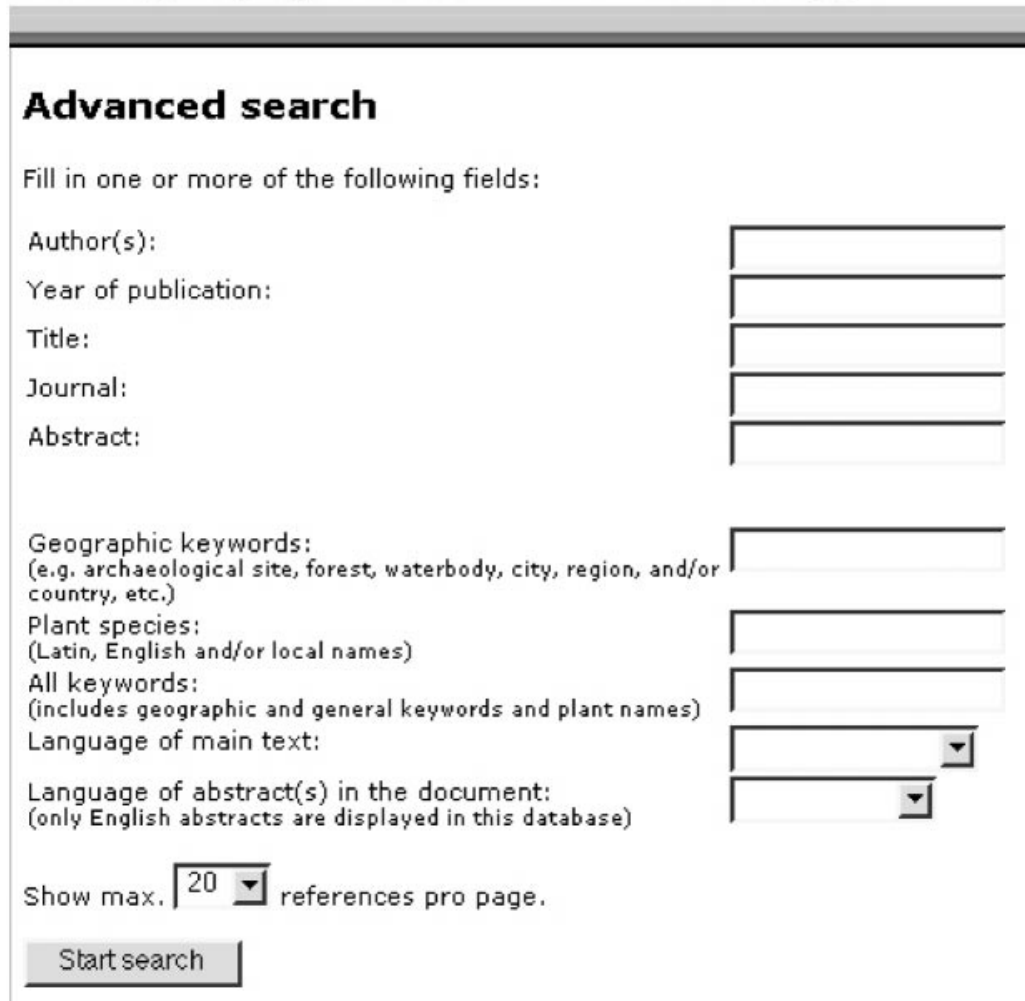

Figure 1. Advanced search interface in the Bibliography of Dendrochronology.

searchable online. In March 2004, a multilingual Glossary of Dendrochronology ${ }^{2}$ was also published on the Internet. Both products were developed with financial support from the Swiss Federal Institute for Forest, Snow and Landscape Research WSL.

\section{THE BIBLIOGRAPHY OF DENDROCHRONOLOGY: 10,000 REFERENCES ONLINE}

Since 1986, the second author of this paper $(\mathrm{H}$. D. G.) has been collecting published material related to tree-ring research and compiling citations with keywords and abstracts into a computer database. As he started distributing monthly refer-

\footnotetext{
${ }^{2}$ Glossary of Dendrochronology: http://www01.wsl.ch/ glossary, cited 01-Apr-04.
}

ence lists on the ITRDB Internet Forum, an increasing number of authors realized how useful this collection was to the international tree-ring community, and contributed reprints of their articles and dissertations. This database soon became-and still is - the ultimate source of bibliographic information for tree-ring scientists worldwide. The original collection was enhanced in 2003 as staff from the WSL Library entered the references of approximately 3,500 documents donated by Professor Fritz H. Schweingruber, who had retired from the Swiss Federal Research Institute WSL.

Only publications that explicitly refer to the description or analysis of tree rings are included (Kaennel Dobbertin and Grissino-Mayer 2004). The online version was launched in February 2003 and had been visited 7,241 times as of April 1, 2004 (Figure 1). As of this date, it held 10,000 


\section{earlywood}

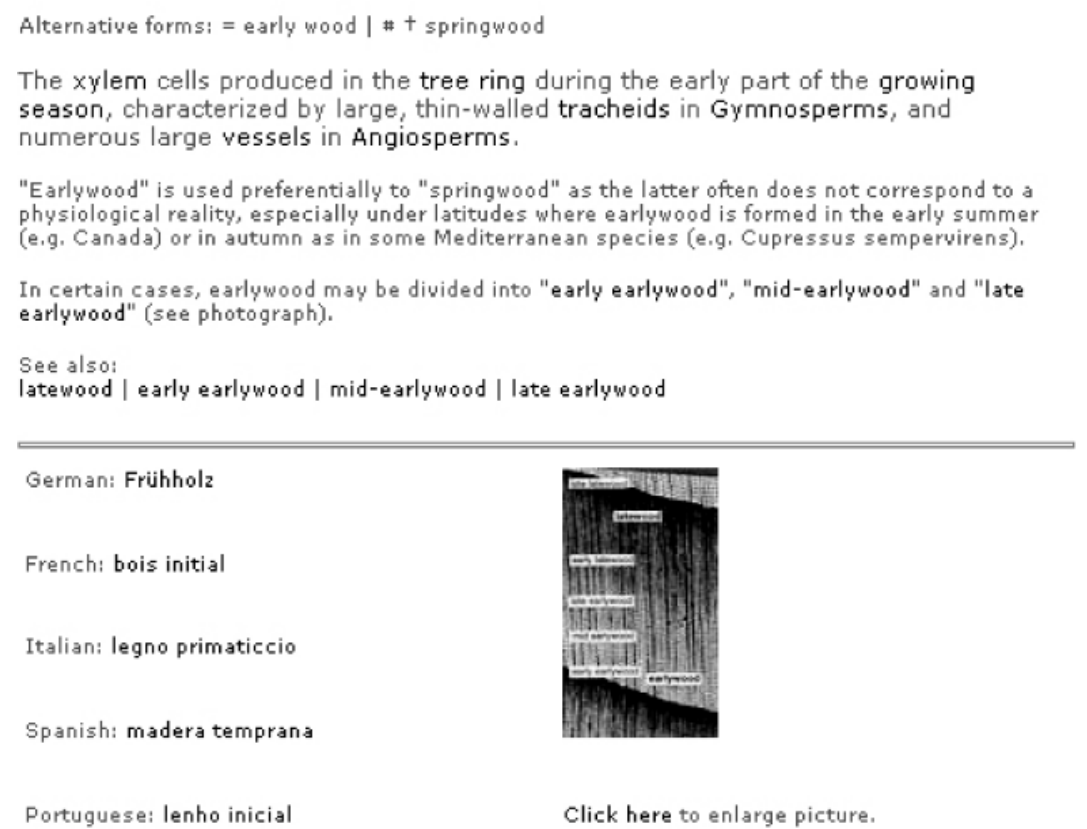

Figure 2. Example of entry in the online Glossary of Dendrochronology. Hyperlinks to other entries are given in bold case.

references in 23 languages and with a year of publication ranging from 1737 to 2004.

The five most cited tree species are Pinus sylvestris (646 references), Picea abies (636), Pseudotsuga menziesii (359), Pinus ponderosa (318), and Abies alba (267). A searchable database of 1,010 plant species relevant for dendrochronolo$\mathrm{gy}^{3}$, with names in Latin, English and partly German, French, Spanish, Italian and Portuguese, accompanies the Bibliography. As an additional service, photocopies of documents from the WSL collection complying with the international copyright laws can be ordered from the WSL Library.

\section{THE GLOSSARY OF DENDROCHRONOLOGY: AN INTERNATIONAL PROJECT IN SIX LANGUAGES}

The searchable online Glossary of Dendrochronology contains definitions of 351 terms in En-

\footnotetext{
${ }^{3}$ Dendrochronology Species Database: http://www01.wsl. $\mathrm{ch} /$ species, cited 01-Apr-04.
}

glish, German, French, Spanish, Italian and Portuguese. In addition, whenever relevant, the following may be found in any of the six languages: variants (for example synonyms, Austrian or Swiss variants of German terms, obsolete terms or neologisms), semantically correlated terms, and linguistic notes. An English technical note and/or a figure may provide further information (Figure 2).

This online tool is adapted from the Multilingual Glossary of Dendrochronology (1995), which included Russian as a seventh language. This publication was a team effort of 53 contributing experts all over the world. English, German and French terms and definitions were compiled or coined by Fritz H. Schweingruber and M. Kaennel Dobbertin by seeking advice and approval from scientists in tree-ring related disciplines and applications. Specifically, Italian, Spanish, Russian and Portuguese-speaking scientists-not translatorstook over the responsibility of the translations or adaptations into their language. When different meanings were highlighted between languages, e.g. for silvicultural terms, the coordinators were instructed to provide a close translation of the En- 
glish definition and a linguistic note to warn readers against the different uses. The justification for this approach is that most of the scientific literature is usually in English, and that non-native English readers unfamiliar with both the language and the scientific content of an article, or non-native English-speaking authors of articles in English may not be aware of differences with their own scientific culture. Pointing out differences between languages rather than hiding them is also the basis for sound terminological work-as it is done for example at IUFRO - and hence for efficient dissemination of scientific results (see e.g. Lund 2002).

The Glossary of Dendrochronology is meant primarily for students and researchers from various backgrounds who apply dendrochronology to a wide range of contexts. It aims at providing them with simple definitions for the most widely used dendrochronological concepts and techniques and for some of the commonest terms used in the many application fields, such as climatology, hydrology or archaeology.

\section{PERSPECTIVES}

Both databases are products of and for the international tree-ring community, and will be kept alive through the input of this community. New entries to the Bibliography of Dendrochronology continue to be added by the second author of this paper. This is mainly possible because of reprints and copies contributed by tree-ring scientists worldwide, whom we thank for their input. The online version is updated monthly by the first author. Tree-ring authors are also invited to submit references for inclusion via an online form ${ }^{4}$. Bib-

\footnotetext{
${ }^{4}$ http://www01.wsl.ch/dendrobiblio/submit.html
}

liographic collections from other tree-ring laboratories worldwide are welcome for inclusion. Although a second printed edition of the Glossary of Dendrochronology is not planned in the near future, comments about use or definitions of terms or suggestions for new entries are encouraged and will be posted on the web site.

\section{ACKNOWLEDGMENTS}

Both online products were developed with the financial support of the Section Long-Term Forest Ecosystems and Ecological Risks at the Swiss Federal Institute for Forest, Snow and Landscape Research WSL in Birmensdorf. The authors thank Matthias Dobbertin and Andreas Rigling (WSL) for their constructive comments on the manuscript.

\section{REFERENCES CITED}

Grissino-Mayer, H. D.

1996-2004: Ultimate Tree-Ring Web Pages 〈http:// web.utk.edu/ grissino/ $>$. Last update: 21-Mar-04. Cited 01-Apr-04.

Kaennel, M., and F. H. Schweingruber

1995 Multilingual Glossary of Dendrochronology. Terms and definitions in English, German, French, Spanish, Italian, Portuguese and Russian. Swiss Federal Institute for Forest, Snow and Landscape Research, Birmensdorf. Paul Haupt Publishers, Berne; 467 pp.

Kaennel Dobbertin, M., and H. D. Grissino-Mayer

2004 The online bibliography of dendrochronology. Dendrochronologia 21(2):85-90.

Lund, G. H.

2002 Coming to terms with politicians and definitions. In Forest Terminology: Living Expert Knowledge, edited by M. Kaennel Dobbertin and R. Prüller. IUFRO Occasional Paper 14:23-44.

Received 16 April 2004; accepted 23 July 2004. 